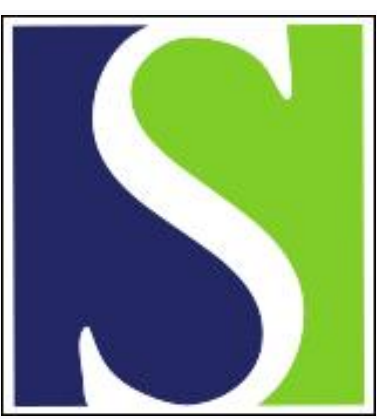

Scand J Work Environ Health 2019;45(3):316-317

https://doi.org/10.5271/sjweh.3815

Published online: 12 Mar 2019, Issue date: 01 May 2019

Development and implementation of interventions managing work-related musculoskeletal disorders: Inadequacy of prevalent research framework and future opportunities by Winkel J, Westgaard RH

Affiliation: Department of Sociology and Work Science, University of Gothenburg, Box 705, SE-405 30, Gothenburg, Sweden. Jorgen.winkel@gu.se

Refers to the following texts of the Journal: 2017;43(6):526-539 2018;44(2):134-146 2018;44(2):111-112

The following article refers to this text: 2019;45(3):318-319

Key terms: ergonomic intervention; ergonomics; evidence; intervention; musculoskeletal disorder; research framework; systematic review

This article in PubMed: www.ncbi.nlm.nih.gov/pubmed/31041996 


\section{Development and implementation of interventions managing work-related musculoskeletal disorders: Inadequacy of prevalent research framework and future opportunities}

In a 2017 article published in the Scandinavian Journal of Work, Environment \& Health (1), van der Beek and coworkers' make the point that workplace interventions have not been overly successful in preventing workrelated musculoskeletal disorders (MSD). They present a research framework consisting of risk identification, consideration of underlying pathophysiological mechanisms, and the development, evaluation, and implementation of interventions to improve this situation. The article complements other papers that concur with the observation that there has been little progress in combating work-related MSD and pointing to deficient research strategies or risk factors insufficiently considered in past projects.

In this Letter to the Editor, we argue that workrelated MSD interventions based on the research framework of van der Beek et al (1) and others are unlikely to have much impact. This is based on the realization, as also expressed in an editorial in the Scandinavian Journal of Work, Environment \& Health (2) that "... in real life, management and not the researcher controls the implementation of workplace interventions."

Research during recent decades provides an empirical basis to state that the potential of rationalization of production systems to cause health problems is large, in contrast to the overall assessment of ergonomic interventions that seem to have limited health effects in the long-term (3). The fact that van der Beek et al (1) do not include this insight/evidence in their framework model illustrates a persistent, too-narrow approach to ergonomic intervention research among specific groups of researchers. Classical research on combating occupational MSD is rooted in the medical research tradition. The elimination of disease is the goal of most ergonomic intervention researchers recruited from the different health professions. They generally represent a research tradition whereby early investigations of risk factors and injury mechanisms are mostly physiological and/or biomechanical. Consequently, quality criteria for occupational intervention studies are adopted from medical research and randomized controlled trials (RCT) are the gold standard of occupational MSD intervention research, as detailed by Kristensen (4). This is also the position of van der Beek and coworkers (1).

However, systematic reviews on ergonomic interven- tion research, which apply strict selection criteria including a strong focus on internal validity and the resulting data loss, may end up with conclusions of low utility. An example is Brewer et al's systematic review (5), which described a rigorous search procedure that pruned $>7000$ articles down to 31 to draw conclusions on workplace interventions for computer users. Their conclusion of a positive health effect of alternative pointing devices among computer users is based on only two studies: one which tested a mouse design that has not been successful in practice and another that substituted a computer mouse with a "trackball". A similar more recent example is Oakman et al's review (6), which identifies 2220 unique studies and ends up with only 17 . These authors are aware of potential significant data loss by restricting their review to studies using RCT design.

Thus, high internal validity of an ergonomic intervention study does not imply that the intervention works when implemented in practice; the external validity may be low, ie, not generalizable to other situations. The issue of "implementation of effective intervention(s)" is considered in box 6 of van der Beek et al's model (1). They highlight the implementation process and its effects by mentioning "... two of the most extensive examples of MSD interventions implementation at the community level ...". Both of these appeared to be unsuccessful. But, as indicated above, the most critical challenge to the implementation of interventions seems to occur at company level (3), and yet van der Beek et al (1) fail to discuss this.

Production systems generally offer ever-changing environments, and a significant part of these changes interact with introduced ergonomic interventions (eg, 3,7 .). The RCT design does not allow for the study of these change processes. Occupational MSD intervention research, carried out in changing environments subject to various influences that are not always recognized, belongs more to the social than the medical domain. Research in the social science tradition tends to use observational or quasi-experimentation designs, often based on natural experiments. Our review of MSD health consequences of production system rationalizations (3) predominantly examined studies based on natural experiments. According to this, we adopted a "best evidence synthesis" approach (8-10) in preference 
to applying strict epidemiological quality criteria.

In conclusion, most of the intervention research aimed at reducing occupational MSD seems to ignore the impact of interventions that aim to improve production system performance (3). This suggests that we need an expansion of the traditional MSD intervention research paradigm; ie, how to involve the stakeholders responsible for interventions that aim to improve production system performance.

A key challenge is now to develop further the research framework presented by van der Beek et al (1) and others to make ergonomic intervention research relevant also to working life. High performance is a prerequisite for the survival of organizations, making production system rationalization a continuous and all-embracing process. We emphasize the wide-ranging impact of rationalizations on worker well-being and therefore suggest a change in the intervention research endpoint from "MSD prevention" to "organizational sustainability", defined as the joint consideration of competitive performance and working conditions in a long-term perspective (3). This needs to be developed in dialog with stakeholders particularly those responsible for production system development (3). The Nordic countries have a long tradition of collaboration between stakeholders with different primary objectives (work environment, efficient production systems, economic success, customer needs, etc), which seems to offer unique opportunities to carry out case studies investigating such issues (11).

\section{References}

1. van der Beek AJ, Dennerlein JT, Huysmans MA, Mathiassen SE, Burdorf A, van Mechelen W et al. A research framework for the development and implementation of interventions preventing work-related musculoskeletal disorders. Scand J Work Environ Health 2017 Nov;43(6):526-39. https://doi. org/10.5271/sjweh.3671.

2. Takala EP. Ergonomic interventions and prevention - a need for better understanding of implementation [editorial]. Scand J Work Environ Health 2018 Mar;44(2):111-2. https://doi.org/10.5271/sjweh.3710.

3. Westgaard RH, Winkel J. Occupational musculoskeletal and mental health: significance of rationalization and opportunities to create sustainable production systems - A systematic review. Appl Ergon 2011 Jan;42(2):261-96. https://doi.org/10.1016/j.apergo.2010.07.002.

4. Kristensen TS. Intervention studies in occupational epidemiology. Occup Environ Med 2005 Mar;62(3):205-10. https://doi.org/10.1136/oem.2004.016097.
5. Brewer S, Van Eerd D, Amick BC 3rd, Irvin E, Daum $\mathrm{KM}$, Gerr $\mathrm{F}$ et al. Workplace interventions to prevent musculoskeletal and visual symptoms and disorders among computer users: a systematic review. J Occup Rehabil 2006 Sep;16(3):325-58. https://doi.org/10.1007/s10926-0069031-6.

6. Oakman J, Neupane S, Proper KI, Kinsman N, Nygård $\mathrm{CH}$. Workplace interventions to improve work ability: A systematic review and meta-analysis of their effectiveness. Scand J Work Environ Health 2018 Mar;44(2):134-46. https://doi.org/10.5271/sjweh.3685.

7. Winkel J, Westgaard RH. A model for solving work related musculoskeletal problems in a profitable way. Appl Ergon 1996 Apr;27(2):71-7. https://doi.org/10.1016/00036870(95)00061-5.

8. Slavin RE. Best evidence synthesis: an intelligent alternative to meta-analysis. J Clin Epidemiol 1995 Jan;48(1):9-18. https://doi.org/10.1016/0895-4356(94)00097-A.

9. Mindell J, Boaz A, Joffe M, Curtis S, Birley M. Enhancing the evidence base for health impact assessment. J Epidemiol Community Health 2004 Jul;58(7):546-51. https://doi. org/10.1136/jech.2003.012401.

10. Ogilvie D, Egan M, Hamilton V, Petticrew M. Systematic reviews of health effects of social interventions: 2 . Best available evidence: how low should you go? J Epidemiol Community Health 2005 Oct;59(10):886-92. https://doi. org/10.1136/jech.2005.034199.

11. Winkel J, Schiller B, Dellve L, Edwards K, Neumann WP, Öhrling T et al. Scientific evidence suggests a changed approach in ergonomic intervention research. In: Osvalder A-L, Blomé M, Bodnar H, editors. Conference Proceedings "Joy at Work". The Nordic Ergonomics and Human Factors Society (NES), Lund; 2017. p 430-36.

Jörgen Winkel, $\mathrm{PhD},{ }^{1,2}$ Rolf $\mathrm{H}$ Westgaard, $\mathrm{PhD}^{3}$

1 Department of Sociology and Work Science, University of Gothenburg, Box 705, SE-405 30, Gothenburg, Sweden.

2 DTU Management Engineering, Building 424, Technical University of Denmark, Kgs. Lyngby, Denmark.

3 Department of Industrial Economics and Technology Management, Norwegian University of Science and Technology, Trondheim, Norway.

Correspondence to: Professor Jörgen Winkel, Department of Sociology and Work Science, University of Gothenburg, Box 705, SE-405 30, Gothenburg, Sweden. [E-mail: jorgen. winkel@gu.se] 